\title{
A FORMAÇÃO DOCENTE PARA A EDUCAÇÃO PROFISSIONAL TÉCNICA E SUA INFLUÊNCIA NA ATUAÇÃO DOS PROFESSORES DO INSTITUTO FEDERAL DO AMAPÁ - CAMPUS MACAPÁ: UM ESTUDO DE CASO.
}

\author{
I. A. C. Guedes ${ }^{1}$, L. B. Sanchez ${ }^{2}$ \\ ${ }^{1}$ Instituto Federal do Amapá - IFAP, Programa de Pós-Graduação em Educação Agrícola - PPGEA \\ ${ }^{2}$ Universidade Federal Rural do Rio de Janeiro - UFRRJ, Programa de Pós-Graduação em Educação Agrícola - PPGEA \\ isabella.carvalho@ifap.edu.br \\ Submetido 05/07/2017 - Aceito 23/10/2017 \\ DOI: $10.15628 /$ holos.2017.6093
}

\section{RESUMO}

O objetivo deste artigo é analisar as influências da formação pedagógica (ou da sua falta) no trabalho dos professores de educação profissional técnica do Instituto Federal do Amapá (IFAP), configurando-se como um estudo de caso, com a finalidade de levantar dados sobre suas práticas pedagógicas e dar visibilidade ao perfil desses profissionais. Destacou-se as questões e dificuldades que envolvem a formação de professores e as especificidades que envolvem o professor que atua na educação profissional tecnológica. Para essa investigação fez-se aplicação de questionários junto aos professores de formação técnica e de formação geral, além da gestão pedagógica, que resultou numa análise de dados e falas confrontadas com reflexões teóricas. A partir disso, foi possível compreender e identificar as concepções sobre a educação profissional, bem como levantar dados com os próprios docentes sobre suas formações, identidades, experiências, práticas, concepções, importância da formação pedagógica para a atuação profissional, dificuldades enfrentadas, entre outras. Nas considerações finais, problematizou-se o que foi abordado e percebido através dos dados coletados, bem como se apresentaram propostas que viabilizem melhorias na formação docente para a educação profissional.

PALAVRAS-CHAVE: Educação Profissional; Formação de professores; Prática docente.

\section{THE TEACHER TRAINING FOR TECHNICAL EDUCATION AND ITS INFLUENCE ON PERFORMANCE OF TEACHERS FEDERAL INSTITUTE OF AMAPÁ - MACAPA CAMPUS: A CASE STUDY.}

\begin{abstract}
The purpose of this article is to analyze the influences of pedagogical training (or lack thereof) on the work of teachers of professional technical education of the Federal Institute of Amapá (IFAP), being configured as a case study, with the purpose of collecting data on Their pedagogical practices and give visibility to the profile of these professionals. It was highlighted the issues, difficulties that involve the training of teachers and the specifics that involve the teacher who works in professional technological education. For this investigation, questionnaires were applied to the teachers of technical training and general training, as well as pedagogical management, which resulted in an
\end{abstract}

analysis of data by means of graphs, charts and speeches confronted with theoretical reflections. From this, it was possible to understand and identify the conceptions about professional education, as well as to collect data with the teachers themselves on their formation, identity, experiences, practices, conceptions, importance of pedagogical training for their performance, difficulties faced, among others. In the final considerations, what has been approached and perceived through the collected data is discussed, as well as presents proposals that enable improvements in teacher education for professional education. 


\section{INTRODUÇÃO}

No cenário da educação brasileira atual, um dos temas mais debatidos é a formação docente, considerada como um dos pontos chaves para elevar o nível da educação no país, diante dos inúmeros questionamentos sobre a qualidade do sistema educacional brasileiro. Ao longo das últimas décadas, tem sido crescente o número de mobilizações, fóruns de debates, dentre outras iniciativas que buscam contribuir para uma formação de professores mais preparados política e pedagogicamente para lidar com a diversidade de saberes, avanços científicos e tecnológicos e com a velocidade das mudanças no conhecimento. No entanto, segundo Moraes e Pedrosa (2009, p.174), as ações ou iniciativas de formação de docentes no Brasil ainda são marcadas por concepções teóricas sem consistência e por políticas públicas de caráter restrito e descontínuo, fato constatado, em especial, para a educação profissional. Com a expansão desta modalidade de ensino, consequentemente cresceram as discussões em torno da formação dos docentes que nela atuam.

O avanço da ciência e tecnologia se reflete diretamente nesta modalidade de ensino, que requer profissionais que atendam suas exigências, dentro de suas especificidades, garantindo a abordagem da dimensão científica e tecnológica, mas também da dimensão cultural, tanto quanto da dimensão do trabalho. Somado a isso, considera-se também a transformação das escolas técnicas, agrotécnicas e Centros Federais de Educação Tecnológica (CEFETs) em Institutos Federais (IFs), caracterizados pela ampliação do seu campo de atuação, desde a educação básica, técnica, tecnológica até o nível superior, com as licenciaturas e cursos superiores de tecnologia ao nível de pós-graduação. Consequentemente, esta mudança requer uma demanda de docentes qualificados, pois um dos fundamentos dos Institutos Federais é a organização pedagógica verticalizada (da educação básica à superior). Ou seja, uma organização que possibilita ao docente atuar em diferentes níveis de ensino, conforme estabelece a classe de Professor do Ensino Básico, Técnico e Tecnológico (EBTT).

Nos Institutos Federais (IFs), consegue-se visualizar alguns perfis diferenciados de docentes, destacando-se, segundo Mathias (2011), dois perfis: os licenciados e os bacharéis. De acordo com essa autora, os primeiros, formados nas disciplinas voltadas para a formação geral, como química, física ou geografia, possuem formação didática, um diferencial positivo, mas quando se trata do ensino médio integrado à educação profissional, atuam nas disciplinas da educação regular sem estarem preparados para a atuação no campo da educação profissional. Um dos problemas vividos por esse grupo é que as licenciaturas nas universidades brasileiras, em geral, não discutem a relação entre o trabalho e a educação e, mais especificamente, a questão da educação profissional em si. Apesar de serem formados para a docência, têm como foco apenas o ensino médio de caráter propedêutico. No grupo dos bacharéis, a situação é agravada: trata-se daqueles professores que atuam nas disciplinas específicas da formação profissional do curso. São, em geral, engenheiros, enfermeiros, médicos, biólogos, que têm o domínio do campo científico no nível da graduação, mas atuam em um curso técnico de nível médio, para o qual não receberam nenhuma formação anterior específica. Neste segundo perfil, caberia destacar também, além dos bacharéis, os tecnólogos. Ou seja, por um lado têm-se os licenciados que não receberam formação para discutir a questão específica da educação e trabalho e, por outro, bacharéis que não dominam os 
instrumentais didáticos e que não tiveram a formação pedagógica necessária para serem professores.

Diante do exposto, consideramos relevante investigar a formação pedagógica dos docentes do Instituto Federal do Amapá e as consequentes influências sobre suas atuações no desenvolvimento da educação profissional técnica realizada no IFAP, com a finalidade de levantar dados sobre suas práticas pedagógicas. Para tanto, foram aplicados questionários para um universo de 26 professores (da formação geral e técnica) do Campus Macapá do Instituto Federal do Amapá, com a finalidade de investigar as concepções e expectativas que eles possuem sobre a docência e sobre o trabalho que desenvolvem na educação profissional técnica, de identificar os direcionamentos para o trabalho nesta modalidade de ensino, bem como de mapear o perfil destes docentes e as dificuldades vivenciadas. Foram aplicados também questionários aos gestores pedagógicos da instituição pesquisada, alcançando 9 (nove) sujeitos da gestão pedagógica, com a intenção de obter informações relacionadas à visão que possuem do trabalho docente na educação profissional técnica, bem como de apontar às dificuldades existentes ou não neste trabalho e identificar se a instituição tem propostas de melhorias para a formação docente voltada para a educação profissional técnica.

\section{PERSPECTIVAS DA FORMAÇÃO DOCENTE PARA A EDUCAÇÃO PROFISSIONAL}

Os investimentos na formação de docentes para a educação profissional técnica começaram a surgir com o processo de industrialização do Brasil, após a década de $30 \mathrm{com}$ o objetivo, conforme afirmam Moraes e Pedrosa (2009, p.175), de preparar a mão-de-obra qualificada para os distintos ramos ocupacionais dos processos produtivos, uma vez que o ensino técnico-profissional organizou-se para adequar-se às necessidades das empresas, sobretudo as do setor industrial [...], identificando-se também a preocupação com o currículo para a formação de professores que nele atuariam, com ênfase na dimensão pedagógico-didática do processo formativo.

Caberia aqui destacar a Lei Orgânica do Ensino Industrial de 1942, que segundo Peterossi (1994), estabeleceu que o professor do ensino profissional necessitava de informações específicas e que as próprias escolas profissionais tinham a responsabilidade de formar seus docentes. Ou seja, desde esse momento previa-se diretrizes para formação dos seus professores através de práticas pedagógicas e educativas (cursos de didática) apropriadas para a educação profissional. Contudo, essa oferta se dava sem caráter obrigatório.

Com a Lei de Diretrizes e Bases da Educação de 1961, houve um pequeno avanço, pode-se afirmar que mínimo, para a formação dos professores do ensino profissional, através dos Cursos Especiais de Educação Técnica. Segundo Machado (2008, p.3-4):

O Parecer CFE no 12/1967 foi o primeiro dispositivo de regulamentação desses cursos especiais de educação técnica e teve basicamente o objetivo de esclarecer sua finalidade. Com base neste Parecer, a Portaria Ministerial no 111/68 esclareceu que tais cursos seriam destinados aos diplomados em nível superior ou em nível técnico em cujos currículos figurassem disciplinas escolhidas para lecionar e definiu o mínimo de 720 horas-aula. 
No final da década de 60 , durante o período da ditadura militar no Brasil, tentou-se profissionalizar a docência na Educação Profissional, com destaque para a Lei 5.540/68, determinando que tanto os professores da chamada Educação Geral quanto os professores do ensino técnico seriam formados em cursos de nível superior. Tomando como base o texto de Cunha (2005), entende-se que quase se acertou nessa profissionalização, mas acabou-se por incorrer no mesmo erro da legislação anterior, quando, por meio do Decreto-Lei no 464 (que complementa a Lei no 5.540/68), aceitou-se que a formação pedagógica fosse substituída por simples "exames de qualificação". Como consequência, as universidades e os estabelecimentos de ensino superior evidenciaram despreparo para promover a formação dos professores.

Diante da exigência das leis acima citadas, ficou notória a carência de professores de ensino técnico, habilitados em nível superior. Para suprir essa carência, foram organizados cursos emergenciais, os chamados Esquemas I e II. "Os primeiros para complementação pedagógica de portadores de diploma de nível superior e os segundos para técnicos diplomados, que incluíam disciplinas pedagógicas do Esquema I e as de conteúdo técnico específico" (MACHADO, 2008, p.4).

Os cursos de Esquema I e II perduraram até a Lei de Diretrizes e Bases da educação nacional no 9394/96. No entanto, cabe ressaltar que até se chegar a esta nova LDBEN, resoluções e pareceres foram estabelecidos no sentido de transformar esses cursos em licenciaturas, mas sem muito êxito. Houve também a transformação das Escolas Técnicas Federais em CEFETs, com "o objetivo de oferecer ensino superior de licenciatura plena e curta, visando à formação de

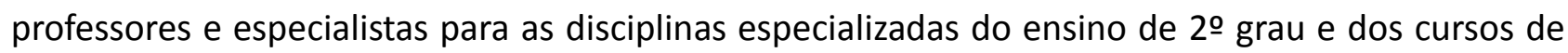
formação de tecnólogos" (MACHADO, 2008, p.5).

Cabe destacar que a LDBEN no 9394/96 não se referiu à Educação Profissional nem como parte integrante da Educação Básica nem como parte da Educação Superior. O ensino médio ficou em um capítulo, referente à educação básica e a educação profissional ficou em outro capítulo, formado por três pequenos artigos, sendo considerada uma modalidade da Educação Básica. Um ano mais tarde, com o decreto no 2.208/97, é que se regulamentou os artigos da atual LDBEN quanto à educação profissional.

No que se refere à docência na Educação Profissional, este decreto representou um grande passo dado, uma vez que exigia, em caráter obrigatório, a formação pedagógica dos docentes desta modalidade de ensino, mesmo àqueles profissionais não docentes que ministravam aulas, os monitores e instrutores. Segundo Machado (2008), estes monitores e instrutores não possuíam curso de licenciatura, mas eram selecionados para a sala de aula principalmente, pela experiência profissional. Dessa forma, considerava-se que a preparação para o magistério não precisava ser prévia, pois poderia se dar em serviço e através de programas especiais de formação pedagógica.

Tais programas foram dispostos pela Resolução CNE no 2/97 que veio complementar o Decreto 2.208/97. Essa formação pedagógica especial equivalia a uma licenciatura, habilitando o profissional a exercer a docência. Em relação a tal organização, Machado (2008) faz uma crítica bem interessante, pois de fato essa formação especial seria oferecida em pelo menos 540 horas, incluindo a parte teórica e prática, sendo a prática com duração mínima de 300 horas. Ou seja, a parte teórica se reduziu ao mínimo de 240 horas e ainda poderia ser oferecida na modalidade a 
distância. Isso nos leva a refletir se tal formação seria suficiente para equivaler ao que é oferecido em uma licenciatura.

Mais tarde, a partir de 2001, com o objetivo de melhor definir o rumo da formação de professores para a Educação Profissional, outros documentos foram entrando em vigor. Cabe destacar, como afirma Ribeiro et al (2011, p.107), que "nesse ano um dos documentos mais importante, por abrir precedentes, foi o Parecer CNE/CEB no 29/01"1. Este parecer trouxe a possibilidade de equiparar os Cursos de Pós-Graduação como formadores de docentes para a Educação Profissional e Tecnológica, o que passou a ser mais um caminho para se trabalhar essa formação, mas que gerou alguns impasses e questionamentos:

Na LDB a proposição é que a formação docente aconteça em cursos de licenciatura, acrescido de, no mínimo, trezentas horas de prática de ensino. Ora, é sabido que as especializações não oferecem estes espaços de prática de ensino e, quando isso acontece, dificilmente esta oferta é de trezentas horas. Mesmo que isso ocorra, ainda há o dispositivo de que a especialização situa-se fora do âmbito da graduação, ou seja, não está alinhado com o disposto na legislação (RIBEIRO et al, 2011, p.108).

O posicionamento destes autores gera uma inquietação e nos faz refletir sobre a complexidade da formação docente para a educação profissional, bem como sobre suas indefinições legais, destacando aqui o decreto $n$ ㅇ 5.154/2004, que ao contrário do decreto $n$ ㅇ 2.208/97, omitiu-se quanto à obrigatoriedade de formação pedagógica para os professores da Educação Profissional. Em relação ao Decreto no 5.154/2004 é importante destacar que ele trouxe contribuições significativas para a Educação Profissional. No entanto, deixou a desejar no que tange à formação docente dessa modalidade de ensino, apesar dos avanços e expansão da educação profissional no Brasil, sobretudo a partir de 2008, quando mudanças significativas aconteceram em sua organização e entendimento.

Observa-se, portanto um cenário de avanços recentes no tocante à Educação Profissional, mas que se fazem acompanhar ainda de carência de pessoal docente qualificado. Tal fato é motivo de indefinições e debates quanto à necessidade de tratar a formação de professores para a educação profissional não como algo pontual, secundário e "especial", como tem ocorrido historicamente, até porque hoje estamos diante de uma dinâmica tecnológica.

Essa complexidade da atuação docente no nível técnico da educação profissional se dá em função das próprias especificidades inerentes a esse nível, pois conforme afirma Machado (2008), quando um professor atua no ensino médio integrado, por exemplo, lhe é exigido realizar uma integração dos conhecimentos científicos, tecnológicos, sociais e humanísticos, que compõem o núcleo comum de conhecimentos gerais e universais, e os conhecimentos e habilidades relativas às atividades técnicas de trabalho, além dos conhecimentos de produção, relativos ao curso técnico em questão. Já nos cursos técnicos na forma subsequente, há a exigência de lidar com um grupo de alunos heterogêneo que já concluiu o ensino médio e que necessita de um reforço da formação

1 Parecer que respondeu a um pedido de autorização do Ministério da Saúde, por meio da Fundação Oswaldo Cruz (Fiocruz) e da Escola Nacional de Saúde Pública, para que seu curso de especialização pudesse habilitar professores na área da Saúde. 
obtida na educação básica, paralelamente ao desenvolvimento dos conteúdos específicos à habilitação técnica.

Diante do exposto, há que se considerar ainda que nos Institutos Federais a realidade é mais complexa, devido ao fato de um professor transitar por vários níveis, formas e modalidades de ensino simultaneamente. Por isso, nossa hipótese é que seja mais complexo aos professores da área de formação profissional atender essas demandas, uma vez que grande parte deles são engenheiros, bacharéis ou tecnólogos, sem formação específica no âmbito educacional. São dotados de um fazer pedagógico que se constrói a partir da experiência profissional específica na área, não vinculada aos conhecimentos pedagógicos sistematizados.

Segundo Abreu (2009) "a formação pedagógica ainda é negligenciada pelas políticas públicas e por muitos professores do ensino técnico. Os professores que contribuem para este pensamento, acreditam que dominam a prática pelos anos que a repetem ao entrar em sala de aula".

Observa-se que esse cenário é comum na esfera da educação profissional, por isso o reconhecimento da necessidade de superação das políticas de formação docente de caráter pontual e emergencial, a fim de que o professor possa de fato compreender as peculiaridades e especificidades da educação profissional, aproximando-se da problemática das relações entre educação e trabalho e estabelecendo no ato de lecionar, as conexões entre as disciplinas e a formação profissional específica.

\subsection{Saberes e Perfil Docente para Educação Profissional atual}

Com as transformações ocorridas no mundo do trabalho e na sociedade atual, exige-se um perfil de trabalhador contemporâneo com determinadas competências básicas e habilidades, saberes específicos, conhecimentos gerais e também técnicos. Segundo Rehem (2009, p.75), "tais mudanças impactam, também, muito diretamente, no professor responsável por formar esse trabalhador, do qual deverá ser exigido um novo perfil de professor para promover essa educação profissional contemporânea". Ou seja, tomando-se por base as concepções e diretrizes para um novo modelo de Educação Profissional e Tecnológica (MEC, 2010), faz-se necessário um perfil de professor que saiba educar para o trabalho e para a vida cidadã, que consiga desenvolver um trabalho integrado, participativo e que articule a competência técnica ao saber-fazer pedagógico.

Como afirma Tardif (2012), o professor ideal seria aquele que conhece sua matéria, sua disciplina e seu programa, além de possuir conhecimentos educacionais e pedagógicos que lhe permitam desenvolver um saber prático baseado em sua experiência cotidiana com os alunos. No entanto, pensar em um professor ideal significa repensar a formação docente, isto é, uma formação que proponha a realização de uma nova articulação entre os conhecimentos produzidos pelas universidades (saberes disciplinares), entre os saberes desenvolvidos pelos professores em suas práticas cotidianas (saberes experienciais) e entre os saberes pedagógicos e didáticos.

Em relação aos saberes pedagógicos e didáticos, há a percepção de que ainda são pouco valorizados pelas políticas públicas e por vários docentes, especialmente os do ensino técnico. 
Contudo, muito já se pontua sobre a importância do estudo da pedagogia no contexto mais amplo da atividade do professor, cabendo destacar as contribuições de Tardif (2012, p.115; 116), segundo as quais:

A pedagogia é o conjunto de meios empregados pelo professor para atingir seus objetivos no âmbito das interações educativas com os alunos. Noutras palavras, a pedagogia é a "tecnologia" utilizada pelos professores em relação ao seu objeto de trabalho (os alunos), no processo de trabalho cotidiano, para obter um resultado (a socialização e a instrução).

Então, na perspectiva de considerar a importância da pedagogia e da formação pedagógica, é que se entende e visualiza na educação profissional técnica a necessidade de um perfil docente que atenda além do saber técnico, o saber pedagógico. Um docente que conheça estratégias e metodologias para desenvolver com competência a educação para o trabalho e para conduzir com êxito os alunos no processo de aprender o trabalho.

$\mathrm{Na}$ esteira do pensamento de Rehem (2009), caberia destacar que no contexto educacional se requer um professor que seja um mediador e que forme profissionais cidadãos. Contudo, a formação desses professores formadores não estaria sobrecarregada apenas de teorias sociológicas, psicológicas, didáticas, filosóficas, entre outras que são trabalhadas, em muitos casos, sem nenhum tipo de relação com o ensino, com o mundo do trabalho e com a realidade prática dos espaços escolares?

A nossa resposta é afirmativa a esta questão. No entanto, em conformidade a Tardif (2012), compreende-se que o caminho não é esvaziar totalmente a lógica disciplinar dos programas de formação para o ensino, pois ela é fundamental. O desafio está em se considerar um espaço maior para os conhecimentos práticos dentro do próprio currículo, no qual se reconheça os alunosfuturos docentes- como sujeitos do conhecimento.

\section{A FORMAÇÃO E ATUAÇÃO DOCENTE NA EDUCAÇÃO PROFISSIONAL DO IFAP- CAMPUS MACAPÁ}

Diante do que foi contextualizado e fundamentado sobre a formação docente para a educação profissional, buscou-se investigar como de fato essa temática se faz presente em uma instituição que atua nesta modalidade de ensino e como tem influenciado na prática docente. Para isso, fez-se necessário analisar as concepções e entendimentos que a equipe responsável pelo trabalho de gestão pedagógica possui sobre a educação profissional e atuação dos professores nesta modalidade de ensino, bem como levantar dados com os próprios docentes sobre sua formação, identidade, experiências, práticas, concepções, dificuldades, entre outras.

Essa pesquisa foi realizada com 26 professores do quadro efetivo do Campus Macapá do IFAP, o que equivale a $27,6 \%$ dos docentes pesquisados, uma vez que até o momento da pesquisa, o campus tinha em seu quadro, um total de 94 docentes. Desses 26 professores investigados, 11 são responsáveis pelas disciplinas técnicas dos Cursos Técnicos em Alimentos (1), Edificações (2), Mineração (6) e Redes de Computadores (2). Esses professores da formação técnica serão identificados neste trabalho como PFT. Os outros 15 professores são responsáveis pelas disciplinas 
de formação geral, dentre os quais estão na pesquisa os das áreas de português (1), matemática (2), química (3), história (1), geografia (1), arte (1), física (1), inglês (2), filosofia (1) e biologia (2), que dependendo da demanda, atuam tanto nos Cursos Técnicos de Nível Médio quanto nos Cursos Superiores. Estes professores da formação geral estão identificados como PFG. Além dos professores, buscou-se investigar os profissionais que realizam trabalho de gestão pedagógica, tais como os coordenadores de curso (2), diretor de ensino (1), diretor de departamento de apoio ao ensino (1), pedagogos (3) e técnicos em assuntos educacionais (2).

\begin{tabular}{|c|c|c|c|c|c|c|c|c|c|c|c|c|c|}
\hline \multirow[b]{2}{*}{ SUJEITOS } & \multicolumn{5}{|c|}{ FAIXA ETÁRIA } & \multicolumn{4}{|c|}{ GRADUAÇÃO } & \multicolumn{4}{|c|}{ PÓS-GRADUAÇÃO } \\
\hline & $\begin{array}{r}25- \\
30 \\
\end{array}$ & $\begin{array}{l}30- \\
35\end{array}$ & $\begin{array}{c}35- \\
40 \\
\end{array}$ & \begin{tabular}{c|}
$40-$ \\
45 \\
\end{tabular} & $\begin{array}{l}45- \\
50 \\
\end{array}$ & Bach. & Licenc. & $\begin{array}{l}\text { Bach. e } \\
\text { Licenc. }\end{array}$ & Tecnólogo & Esp. & Mest. & Mestrand. & Dout. \\
\hline $\begin{array}{c}\text { Gestores Pedagógicos } \\
\text { (9) }\end{array}$ & 2 & 5 & 1 & 1 & - & 3 & 6 & - & - & 4 & 3 & 2 & - \\
\hline \multicolumn{14}{|l|}{ PROFESSORES } \\
\hline $\begin{array}{c}\text { Professores } \\
\text { Da Formação Técnica } \\
\text { (11) }\end{array}$ & 3 & 4 & 1 & 2 & 1 & 4 & - & 1 & 6 & 3 & 7 & - & 1 \\
\hline $\begin{array}{c}\text { Professores } \\
\text { Da Formação Geral } \\
\text { (15) }\end{array}$ & 3 & 5 & 5 & 2 & - & 2 & 12 & 1 & - & 3 & 4 & 6 & 2 \\
\hline $\begin{array}{c}\text { Total de professores } \\
\text { (26) }\end{array}$ & 6 & 9 & 6 & 4 & 1 & 6 & 12 & 2 & 6 & 6 & 11 & 6 & 3 \\
\hline
\end{tabular}

Quadro 1- Dados de identificação dos sujeitos investigados

Fonte: Resultados dos questionários aplicados de fevereiro a junho de 2014.

A partir da identificação dos sujeitos é possível observar que tanto a gestão pedagógica quanto o corpo docente estão concentrados numa faixa etária jovem (30-35anos). Quanto ao corpo docente, confirma-se o perfil visualizado em muitos Institutos Federais (IFs): há os licenciados, os bacharéis e também os tecnólogos, que vêm ocupando bastante espaço na carreira docente em IFs. Há uma concentração de professores bacharéis e tecnólogos na área da formação técnica e licenciados na área da formação geral.

Além disso, é interessante destacar que o maior grau de titulação (mestrado e doutorado) está com os professores da formação técnica. Essa condição, conforme revelado nesta pesquisa, faz com que alguns desses professores não considerem importante e produtivo a formação pedagógica através de cursos que venham complementar a sua prática em sala de aula por meio de estudos de teorias da educação, psicológicas e didático-pedagógicas, bem como de orientações metodológicas e estratégias de ensino e avaliação. Mas o IFAP, considerando essa realidade, tem exigido em seus editais para concursos de professores efetivos, a formação pedagógica (licenciatura, complementação), sendo que mesmo o docente possuindo mestrado ou doutorado terá que fazê-la, conforme prazo estabelecido pela instituição através de edital.

Antes de serem apontadas as concepções e os posicionamentos acerca das questões de formação pedagógica e prática docente que permeiam a educação profissional, faz-se jus conhecer 
alguns dados sobre o percurso, as experiências, e transformações na carreira destes docentes, a fim de analisar de que forma podem ou têm influenciado em sua prática. A maioria dos professores do IFAP, tem experiência na docência num intervalo entre 5 a 15 anos e ingressaram na carreira docente atuando no nível superior. Mas ao observar por área de atuação, constata-se que os professores da formação técnica possuem menor tempo de exercício da docência, concentrado entre 5 e 10 anos, enquanto os professores da formação geral já possuem tempo maior, entre 10 a 20 anos no nível fundamental.

Apesar dos professores da formação geral possuírem mais anos de experiência, são poucos os que atuaram na educação profissional antes de ingressar na instituição analisada. Por outro lado, do total de $38 \%$ dos professores que possuem experiência na educação profissional, $23 \%$ são da formação técnica, no qual já atuaram em Cursos de Educação Profissional, inclusive em outros Institutos Federais, o que consequentemente colabora para o desenvolvimento da sua prática nesta modalidade de ensino.

Esse cenário nos leva à compreensão de que, assim como existem professores sem a formação pedagógica para exercer a docência, há também os professores com a formação pedagógica, mas sem a experiência docente na modalidade de educação profissional. No entanto, ambos possuem experiências, ou seja, saberes da experiência, que segundo Pimenta (2002, p.20): "são também aqueles que os professores produzem no seu cotidiano docente, num processo permanente de reflexão sobre sua prática, mediatizada pela de outrem - seus colegas de trabalho, os textos produzidos por outros educadores".

A pesquisa revelou ainda que dos 26 docentes investigados, 3 (três) já atuaram como técnicos da área antes de ingressarem na docência (professores da formação técnica). No contexto atual, 3 (três) exercem ambas as funções (sendo 1 professor da formação técnica e 2 da formação geral), mas todos se reconhecem profissionalmente como docentes. Este fato traduz um dos eixos fundantes na formação do professor de educação profissional, apontados pela autora Cleunice Rehem (2009, p. 111), que são os "saberes disciplinares, saberes da experiência profissional e saberes pedagógicos". No caso em questão, refere-se ao saber da experiência profissional, importante na perspectiva de que "ensinar a trabalhar numa dada área requer, necessariamente, saber como se dá o trabalho naquela área, incluindo aí seus processos produtivos, suas exigências reais, suas contradições, seus avanços tecnológicos, suas relações no mercado de trabalho" (REHEM, 2009, p.110).

Alguns professores, sobretudo da formação técnica (bacharéis e tecnólogos), possuem essa experiência de "chão de fábrica", de empresas, de gerenciamento de obras, entre outras, conforme a área e consideram que esse saber experiencial seja suficiente para sua atuação como professor. Mas ao mesmo tempo, identificam-se professores que reconhecem a existência de um público na educação profissional com especificidades e que vai lhes exigir educar para o trabalho abordando uma formação integral do homem, e para isso, necessitarão dominar além desse saber da profissão que os alunos estão aprendendo, o saber ensinar (didático-pedagógico) e o saber disciplinar (dos conteúdos da área). 
Em relação à equipe de gestão pedagógica investigada, todos têm o entendimento de que esta modalidade de ensino deve estar voltada para a formação profissional, para a realidade do mundo e mercado de trabalho, mas que, sobretudo, tem a responsabilidade de preparar jovens profissionais através de uma educação com princípios humanos e cidadãos. Ou seja, a educação profissional deve formar técnicos, no entanto, não apenas técnicos que "apertam parafusos", mas técnicos intelectuais, seres pensantes que sejam capazes de desenvolver as competências de saber-fazer, saber-ser e saber-conviver.

Quanto aos professores, pode-se observar que entre os da formação técnica e da formação geral há uma concepção em que predomina as seguintes palavras-chave: mercado de trabalho, soluções inteligentes e rápidas para problemas, ensino mais exigente, desenvolvimento de competências e preparação para uma função/profissão. Sendo que são poucos os que abordam uma visão para além do mercado de trabalho, citando que se trata também de uma modalidade que visa garantir a formação de cidadãos críticos e reflexivos e profissionais capazes de entender o todo dos processos em que atuam.

Em relação ao grau de satisfação da formação didático-pedagógica do docente para atuar na educação profissional, sobre as contribuições que uma formação pedagógica pode trazer no trabalho docente, sobre de que forma ela pode ser importante e produtiva em sua atuação, bem como se estes professores têm se atualizado/capacitado para exercer a docência nesta modalidade de ensino, os resultados obtidos nessa pesquisa constatam que, tanto na avaliação dos gestores pedagógicos, quanto na avaliação do total de professores, predomina a visão de que a formação didático-pedagógica é parcialmente satisfatória (55,6\% e 57,7\% respectivamente). Os primeiros consideram que entre os professores da formação técnica há a ausência de uma formação pedagógica. Ou seja, a ausência dessa formação acaba se refletindo, sobretudo, nas licenciaturas, nas quais os professores por terem uma formação de bacharel ou tecnólogo acabam direcionando o curso como se fosse um bacharelado, não relacionando com os aspectos educacionais e práticas pedagógicas de como ensinar, porque ensinar e o que ensinar.

Mas esses sujeitos também apontam que, apesar de alguns professores da formação técnica não possuírem a formação pedagógica e os professores das duas áreas apresentarem possíveis dificuldades em sala de aula, há o interesse e busca por cursos e atualizações, além de procurarem o suporte de profissionais, da própria instituição, que detêm conhecimentos pedagógicos e do processo ensino-aprendizagem: os pedagogos.

No que tange às colocações dos professores, a maioria justificou o fato de sua formação didático-pedagógica ser ainda parcialmente satisfatória por considerarem que precisam de mais momentos de estudo e debate em relação à educação profissional; por haver ainda insegurança e o tempo às vezes não permitir maior dedicação; porque o tempo ainda está trazendo a experiência e a formação continuada que lhes propiciará uma melhor compreensão da educação profissional; porque os conhecimentos pedagógicos ainda estão sendo adquiridos na prática de sala de aula e por considerarem que as universidades ainda pecam na formação de professores sem uma abordagem prática das várias especificidades de ensino como educação especial, profissional, fazendo com que muitas vezes o professor se interesse por tal realidade apenas quando está na sala de aula ou que se torne um professor frustrado. 
A respeito da formação de professores no Brasil, a autora Gatti $(2012$, p.18) destaca que nos cursos de licenciatura, "os espaços destinados às práticas docentes não são utilizados de fato, onde se poderia aliar experiência e teoria e fazer esta rica aliança entre conhecimento acadêmico e conhecimento que vem com o exercício da profissão e as experiências vividas em situações escolares na educação básica".

Ainda fazendo referência à opinião dos professores quanto ao grau de satisfação da formação didático-pedagógica, foi bem equilibrada a porcentagem dos que a consideram satisfatória e amplamente satisfatória. Entretanto, chamou a atenção o fato de que do total de professores que a consideram amplamente satisfatória, $15,4 \%$ são da formação técnica, não possuem formação pedagógica e também não a acham fundamental, no qual consideram suficiente a prática adquirida no cotidiano de sala de aula.

A respeito disso, considerou-se pertinente também saber da gestão pedagógica, que acompanha diretamente os professores, se percebem a ocorrência de resistência por parte dos professores sem formação pedagógica em receber orientações, acompanhamento e formação. A maioria (55,6\%) aponta que há um grau médio de resistência e dizem identificá-la no acompanhamento ao professor. Diante disso, como sugestão, a própria equipe pedagógica poderia elaborar um programa de formação com esses professores que apresentam possíveis resistências, conscientizando-os e fazendo-os perceber a importância do saber pedagógico em sua prática. Cabe destacar também que a gestão pedagógica, já sentiu mudanças positivas na prática pedagógica dos docentes que fizeram a complementação pedagógica na forma de Pós-Graduação em Docência na Educação Profissional e Tecnológica, ofertada pelo IFAP.

Quanto aos professores, $88,5 \%$ consideram que a formação contribui e $84,6 \%$ que é importante e produtiva no trabalho docente, sendo essa maioria composta por $100 \%$ dos professores da formação geral, que já são licenciados. Para estes, a formação pedagógica faz toda a diferença, pois apresentam certas técnicas de leituras, de planejamento, promovem discussões científicas sobre a área educacional e especificamente sobre a atuação docente e relação professor-aluno, entre outras contribuições para prática docente, apesar de não serem direcionadas para a educação profissional, visto que não tiveram esse direcionamento em sua formação, nas universidades. Já os professores que possuem um discurso negativo sobre essa formação, todos são da área técnica. Conforme dados obtidos nos questionários, estão entre os que não possuem formação pedagógica, sendo que $11,5 \%$ consideram que a formação não contribui e 15,4\% não consideram importante e fazem ou farão por exigência.

Por outro lado, percebe-se também algo bastante interessante, que é o fato de outros professores da área técnica, bem como os que são da formação geral, mas são bacharéis, terem feito complementação pedagógica e agora apresentarem outro olhar para essa formação. Diante desses resultados, pode-se afirmar como o pensamento e a prática do docente mudam quando ele passa ter o contato com uma formação pedagógica, deixando para trás a ideia de que essa formação é desnecessária, sem importância e uma "receita de bolo". Tal formação os faz caminhar rumo a uma melhor compreensão do processo de ensino-aprendizagem e à reflexão sobre suas metodologias, avaliação, didática, entre outros aspectos. 
Nessa perspectiva, entende-se que há necessidade e importância de uma formação pedagógica continuada para os professores com o propósito de que eles desenvolvam competências de mediação da aprendizagem no contexto do seu campo específico de conhecimento. Entretanto, para que isso de fato se torne realidade, é fundamental que os programas de formação didático-pedagógica de professores sejam organizados de maneira a fazer com que o "aluno-professor aprenda a fazer a transposição didática dos saberes disciplinares para o nível de ensino em que atuará, saiba preparar uma sequência pedagógica para fazer aprender e ter o domínio do referencial profissional da conclusão que irá ensinar" (REHEM, 2009, p.120).

Dessa forma, se teria um grande ganho na atuação do professor na educação profissional, visto que ele passaria ter a habilidade de adequar os conteúdos a essa modalidade de ensino, tornando-os ensináveis e contextualizados no mundo do trabalho. Ou seja, isso seria fruto de uma formação que provocou uma renovação e transformação na prática docente.

Para demonstrar a necessidade de um perfil profissional docente mais completo para atuar na educação profissional, destacamos a contribuição de Machado (2008, p.11), que diz que:

O professor da educação profissional deve ser capaz de descrever práticas profissionais (como, por quem e dentro de que condições uma atividade é realizada), de levar em conta o uso que quer fazer desta descrição no processo de ensino-aprendizagem (tipo de apropriação e grau de utilização das técnicas) e de estabelecer a diferença entre ensinar práticas e ensinar os saberes sobre estas práticas (construção mais ou menos elaborada, mais ou menos formalizada destas práticas).

Sendo assim, fica evidente que a formação pedagógica se faz necessária e apenas os diplomas de mestrado ou doutorado não são suficientes para atuação na Educação Profissional, pois estes são realizados como forma de aprofundar o conhecimento específico adquirido na graduação. Por exemplo, um professor graduado em Engenharia Civil tende a procurar um mestrado nessa área. Enquanto uma complementação pedagógica na forma de pós-graduação lato sensu é organizada com características diferenciadas, com carga horária superior a 360 horas trazendo os saberes das teorias educacionais, da didática, os sociais, os princípios psicopedagógicos e a prática docente através de estágios, a fim de garantir a articulação dos saberes pedagógicos inerentes ao cotidiano escolar às especificidades da educação profissional.

\subsection{Dificuldades e Desafios na Docência em Educação Profissional}

Diante do exposto sobre as questões que permeiam a formação e prática docente na educação profissional, tratamos das dificuldades e desafios que os docentes da instituição pesquisada consideram fazer parte de sua atuação. As principais dificuldades apontadas estão relacionadas mais aos aspectos infraestruturais e organizacionais. Ou seja, os professores não viram como dificuldade o trabalho de sala de aula, sua prática pedagógica e os aspectos metodológicos.

Outra dificuldade a qual cabe uma observação é a que se refere ao excesso de carga horária. Na realidade, o que acontece na instituição é que os professores têm uma média de 15 horas, sendo poucos com o máximo de 24 horas permitido por lei. No entanto, alguns afirmam ser "excesso" pelo fato de serem professores EBTT e atuarem em uma instituição que trabalha com 
níveis, formas e modalidades diversificados. Com isso, os professores da formação técnica assumem diferentes disciplinas (de 3 a 6 ) em turmas de níveis e formas diferentes, cada uma com sua especificidade, e os professores da formação geral, apesar de serem de português, matemática, química, etc, também atuam em vários níveis, formas e modalidades dentro da instituição, tendo que fazer e adaptar seu planejamento, várias vezes e atender às especificidades de cada público.

Além dessas dificuldades, destacadas e vivenciadas pelos professores, a gestão pedagógica identifica desafios para a atuação deles na educação profissional que se cruzam com as dificuldades apontadas por eles, tais como carga horária alta em sala; o que dificulta o professor se preparar melhor ou investir na formação; desinteresse dos servidores de educação para as orientações iniciais do que se propõem a educação profissional, objetivos, entre outros que a instituição oferece; estágio, nivelamento dos alunos; a valorização do docente como profissional, a formação pedagógica de alguns professores e a necessidade de construir uma educação profissional técnica inclusiva, que trabalhe as especificidades dos educandos.

Essas questões apontadas pela gestão pedagógica levam a constatação de que a equipe pedagógica, onde se encontram profissionais da área de educação como pedagogos e Técnicos em Assuntos Educacionais (TAEs), também precisa ser capacitada, conhecer de fato as especificidades da educação profissional e, consequentemente, dar o suporte e contribuir na formação continuada do corpo docente, sendo importante também estes docentes buscarem maior formação didáticopedagógica.

\section{CONSIDERAÇÕES FINAIS}

A partir dessa pesquisa, constatou-se que existe uma lacuna na formação inicial de professores, e quando se observa professores atuando na educação profissional, percebe-se que provavelmente eles terão mais dificuldades na prática pedagógica, pois irão se ver diante de uma modalidade de ensino com características e especificidades nas dimensões científica e tecnológica, bem como nas dimensões cultural e do trabalho, que na maioria das vezes não são contempladas nos cursos de formação de professores.

Nesse contexto, identificou-se que há um desafio em nível institucional, no sentido de sensibilizar uma pequena parcela de professores do IFAP - Campus Macapá sobre a relevância da formação pedagógica. Por isso, sugere-se como caminho inicial, que a própria equipe pedagógica da instituição possa elaborar um programa de formação com esses professores que apresentam possíveis resistências, conscientizando-os e fazendo-os perceber a importância do saber pedagógico em sua prática, tomando como ponto de partida as Novas Diretrizes Curriculares Nacionais para a Educação Profissional Técnica de Nível Médio, que aborda a formação docente e amplia as possibilidades em que ela pode ser alcançada.

Com base nos dados coletados, afirmamos que a formação pedagógica e continuada mostra-se como o caminho para auxiliar principalmente aqueles professores que não possuem a formação pedagógica na atuação da educação profissional, a fim de que consigam atender as 
necessidades contextuais e pedagógicas, as mudanças tecnológicas, as transformações do mundo do trabalho e exigências do mercado de trabalho desta modalidade e desenvolvam competências de mediação da aprendizagem.

Este estudo buscou também apresentar propostas que viabilizem melhorias na formação docente para a educação profissional técnica, considerando algumas possibilidades baseadas nas contribuições de Moura (2006, p.86), quando afirma ser necessário "produzir conhecimento nesse novo campo, estimulando a criação de grupos de pesquisa e programas de pós-graduação vinculados à formação desses profissionais".

Nessa perspectiva, sugere-se a montagem de um programa de capacitação, de pelo menos 40 horas, na primeira semana dos professores recém-chegados à instituição, uma espécie de "Semana de Formação". Essa capacitação inicial poderia ser organizada pela própria equipe técnico-pedagógica do IFAP, além de ser possível a contribuição de outros servidores da Rede Federal de Educação Profissional nesse processo. Acredita-se que esse momento seria fundamental para situar o docente nessa modalidade de ensino, que possui suas especificidades, sendo apenas o primeiro passo de um longo caminho formativo a ser percorrido.

No decorrer do tempo, poderiam acontecer também ciclos de estudos, mensais ou bimestrais, sobre diversas temáticas inerentes à atuação docente na educação profissional. Além disso, a instituição poderia contar com o suporte da Educação a Distância (EAD), através da Plataforma Moodle, na qual seria possível lançar fóruns de discussões, situações-problemas vivenciadas em sala de aula, textos complementares que pudessem ajudar na prática docente e também funcionaria como um canal para melhor facilitar a comunicação entre o corpo docente e equipe técnico-pedagógica.

A realização de fóruns permanentes de formação pedagógica para os professores seria também um bom caminho, principalmente porque poderia possibilitar um espaço de discussão, orientação e produção de conhecimento com vistas a uma prática pedagógica inovadora. No entanto, cabe ressaltar que essas propostas exigem inicialmente a capacitação do corpo técnico pedagógico, a fim de que possa contribuir com eficiência no processo de formação docente.

Outra possibilidade, que seria uma contribuição da instituição na formação de futuros professores que possam atuar na educação profissional, é contemplar no currículo dos seus cursos de licenciatura os conhecimentos inerentes à educação profissional em seus aspectos teóricos e práticos, como por exemplo, proporcionando estágios aos futuros docentes nesta modalidade de ensino.

Considera-se que esta pesquisa pode contribuir no sentido de estimular a reflexão sobre a necessidade de aprofundar discussões que levem ao estabelecimento de uma política de formação inicial e continuada dos professores do ensino técnico, que pode ser iniciada por iniciativa das próprias instituições de ensino. 


\section{REFERÊNCIAS}

Abreu, Guacira Ribeiro de (2009, S.d). Ressignificação da Formação do Professor de Ensino TécnicoProfissional: por uma prática reflexiva na reconstrução de sua identidade. Revista Profissão Docente On-line, Uberaba, v.9, no21 (pp. 114-132). Recuperado de http://www.revistas.uniube.br/index.php/rpd/article/view/231.

Lei no 9394 / 1996. (1996). Estabelece as diretrizes e bases da educação nacional. Brasília, 1996. Recuperado em 17 janeiro, 2012 de: http://www.planalto.gov.br/ccivil_03/LEIS/I9394.htm

Cunha, L. A. (2005). O Ensino industrial - manufatureiro no Brasil: origem e desenvolvimento. In: Junior, Waldemar de Oliveira (2008) . A formação do professor para a educação Profissional de nível médio: tensões e (in)tenções (Dissertação de Mestrado, Universidade Católica de Santos, Santos). Recuperado de http://biblioteca.unisantos.br:8181/bitstream/tede/127/1/Waldemar\%20de\%200liveira\%20Ju nior.pdf

Gatti, Bernardete A (2012). Políticas e Práticas de Formação de Professores: Perspectivas no Brasil. In UNICAMP ( ed.), 16 Encontro nacional de didática e práticas de ensino, Livro 2 (pp 16-32). Campinas: Junqueira\&Marin. Recuperado em 10 setembro, 2013 de http://www2.unimep.br/endipehttp://www2.unimep.br/endipe

Machado, Lucília Regina de Souza (2008, Junho). Diferenciais inovadores na formação de professores para a Educação Profissional. Revista Brasileira da Educação Profissional e Tecnológica, v. 1, n.1 (pp. 8 -22). Recuperado de http://www.portal. mec.gov.br/setec/arquivos/pdf3/rev_brasileira.pdf.

Mathias, Maíra (2011). Quem é o docente da educação profissional? [PDF]. Fundação Oswaldo Cruz: Rio de Janeiro. Recuperado 25 julho, 2012 de http://www.epsjv.fiocruz.br/index.php?rea=Noticia\&Num=535

Moraes, Lélia Cristina S. de \& PEDROSA, Elaine Maria P (2009). A formação de Professores para a Educação Profissional: um debate necessário. In CHAVES, Vera Lúcia Jacob; CABRAL NETO, Antonio \& NASCIMENTO, Ilma Vieira. (Orgs). Políticas para a educação superior no Brasil: velhos temas e novos desafios. São Paulo: Xamã.

Moura, Dante Henrique. PROEJA: formação técnica integrada ao Ensino Médio. In: Ministério da Educação: Brasília, 2006. Recuperado em 10 agosto 2012, de http://portal.mec.gov.br/setec/arquivos/pdf2/boletim_salto16.pdf

Peterossi, Helena Gemignani (1994). Formação do Professor para o Ensino Técnico. São Paulo: Edições Loyola.

Pimenta, Selma Garrido (2002). (Org.) Saberes pedagógicos e atividade docente. São Paulo: Cortez. Rehem, Cleunice Matos (2009). Perfil e formação do professor de educação profissional técnica. São Paulo: Editora Senac.

Ribeiro, Rosa A. J., Simionato, Margareth F., Gomes, Marta Q., Zank, Claudia., Ambrosini, Bianca B., Heckle, Gisele L. (2011, S. d). Questões que permeiam a formação de professores na educação profissional técnica de nível médio. Revista Teoria e Prática da Educação, v. 14, $n$. 3 (pp. 97-110). Recuperado de http://periodicos.uem.br/ojs/index.php/TeorPratEduc/article/view/14770

Tardif, Maurice (2012). Saberes Docentes e Formação Profissional. Petrópolis, RJ: Vozes. 